\title{
The Prevalence of Trauma Injuries From Neighboring Countries Transferred to Iran
}

\author{
Hadi Khoshmohabat', Hamid Reza Rasouli', Mohammad Javad Forozanmehr', Mohammad Hosein \\ Kalantar Motamedi', Masoud Saghafinia ${ }^{1}$
}

${ }^{1}$ Trauma Research Center, Baqiyatallah University of Medical Sciences, Teharan, Iran

Corresponding Author: Masoud Saghafinia, MD, Associate Professor, Trauma Research Center, Baqiyatallah University of Medical Sciences, Tehran, Iran. Tel: +98-21-88053766, Email: dr_saghafi@bmsu.ac.ir

Received April 15, 2017; Accepted November 21, 2017; Online Published December 4, 2017

\begin{abstract}
Introduction: In recent years, the prevalence of attacks perpetrated by humans against other humans has increased worldwide. The injuries suffered by attack victims are severe and multi-organ. Iran's neighboring countries have been the scenes of attacks in the recent past. This study assessed the type and severity of injuries sustained by victims transferred to Iran during the time period 2005-2007.

Methods: This study was conducted on injured civilians transferred to hospitals in Iran. Data regarding cause of injury, type and severity of injuries, diagnostic-therapeutic interventions, and patient outcomes was collected and statistically analyzed using SPSS version 14 software.

Results: In the studied time period, 214 attack victims were transferred to 3 Level 1 trauma centers in Iran. The mechanisms of injury were explosion in 130 cases, gunshot in 48, and other causes in the remaining victims. The mean Injury Severity Score (ISS) was $5.91 \pm 4.54$ (range $=1-34)$, and the median was 4; 109 cases (51\%) had an ISS between 1 and 8, 73 cases (34\%) were scored between 9 and 14,15 cases ( $7 \%$ ) were scored from 16 to 24 , and 17 cases ( $8 \%$ ) had an ISS $\geq 25$. In terms of the number of injured organs, 42 patients (20\%) had one, $124(58 \%)$ had 2, $36(17 \%)$ had 3, and 12 patients (5\%) had 4 or more injured organs. Procedures included 86 orthopedic, 25 general surgical, 21 ear, nose, and throat (ENT), 18 plastic, 15 neurosurgical, and 10 ophthalmic operations; 25 patients received psychiatric counseling. The mean $( \pm \mathrm{SD})$ hospital stay was $13.43( \pm 19.76)$ days $($ range $=1-230)$.

Conclusion: The injury pattern in attacks is more severe and differs from other traumas. The medical team should have adequate knowledge in this respect to provide comprehensive healthcare.

Keywords: Trauma, Pattern of Injury, Severity of Injury
\end{abstract}

Citation: Khoshmohabat H, Rasouli HR, Forozanmehr MJ, Kalantar Motamedi MH, Saghafinia M. The prevalence of trauma injuries from neighboring countries transferred to Iran. Int J Travel Med Glob Health. 2017;5(4):140-143. doi:10.15171/ijtmgh.2017.27.

\section{Introduction}

Trauma is among the main causes of death in developing countries. Annually, about 5 million people die as the result of intentional or unintentional trauma worldwide. In recent years, due to an increase in the number of attacks, the incidence of this type of injury has risen and become a threat to global healthcare. The term "attack" is defined as an aggressive and violent action against a person for various reasons injuring or killing one or more people. ${ }^{1-3}$ Bombs are the most common source of injury. ${ }^{4}$

Explosives are usually placed alongside the road. Previous studies have shown that bomb injuries differ from other forms. They are more complex, more severe, dependent upon the type of weapon, ${ }^{3,5-7}$ and require more medical intervention and rehabilitation. However, most emergency units are not prepared to provide healthcare to bomb victims. The medical team must be acquainted with the physics of these injuries. Although several articles have been published regarding attacks, ${ }^{3,46-11}$ few studies on civilian attacks transferred to Iran were found. The current study sought to assess the cause, type, and severity of injuries, diagnostic and therapeutic interventions, and outcomes of civilian victims of terrorist attacks from countries neighboring Iran who were transferred to hospitals in Iran.

\section{Methods}

Two hundred fourteen injured civilians were transferred to 3 Level 1 trauma centers in Iran and treated there during the time period 2005-2007. Data relative to demographic information, incident location, injury type, severity, 
therapeutic interventions, and outcomes was collected by trained physicians. Patients who had been transferred to Iran for reasons other than attacks were excluded. Injuries were determined based on similar studies and standard global indices (Injury Severity Score, ISS) and were analyzed using SPSS version 14 software.

\section{Results}

Two hundred fourteen civilian victims, 182 males (85\%) and 32 females (15\%), were transferred to Iran from neighboring countries and treated. The mean \pm SD age of patients was $30.84 \pm 11.19$ years (range $=2-61$ years). Of all patients, 119 (55.6\%) were admitted to orthopedic wards, 34 (15.9\%) to general surgery, $26 \%$ to plastic surgery, $19(8.9 \%)$ to neurosurgical wards, $16(7.5 \%)$ to ophthalmology, 7 (3.3\%) to ear, nose, and throat (ENT), 7 (3.3\%) to maxillofacial surgery, and $5(2.3 \%)$ to the internal medicine ward. The incident site in 52 cases was a city; the mechanism of trauma was explosion in 130 cases $(64.7 \%)$, gunshot in $48(23.9 \%)$, hitting a hard object in $5(2 \%)$, mine explosion in $1(0.5 \%)$, cuts in $2(1 \%)$, burns in $8(4 \%)$, and other mechanisms in 7 cases $(3.5 \%)$. Forty-seven cases had high-velocity gunshot wounds; 117 (54.7\%) patients were transferred from the border to Tehran by plane.

No data was available regarding the diagnostic or therapeutic interventions performed before the arrival of these patients in Tehran hospitals. Of the 140 patients who had complete medical records, cardiopulmonary resuscitation and tracheal intubation were performed in 2 and 6 cases (2.8\%), respectively, before hospital admission in Tehran. The following procedures were performed in hospital emergency units: cardiopulmonary resuscitation in $2(1 \%)$ cases, tracheal intubation in $8(3 \%)$ cases, and prevention of bleeding in 90 $(42 \%)$ cases. The mean ISS was $5.91 \pm 4.54$ (range $=1$ to 34$)$. The median ISS was 4 . ISS classification was as follows: 109 cases (51\%) had an ISS between 1 and 8, 73 cases (34\%) had an ISS between 9 and 14, 15 (7\%) had an ISS between 16 and 24 , and 17 ( $8 \%$ ) had an ISS $\geq 25$ (Table 1).

The top 6 most commonly injured organs were skin in 160, limbs and skeletal pelvis in 131, face in 49 , head and neck in 33 , abdomen and visceral pelvis in 36 , and chest in 18 victims (Figure 1). The number of organs injured per victim was 1 in $42(20 \%), 2$ in $124(58 \%), 3$ in $36(17 \%)$, and 4 or more in $12(5 \%)$ patients (Table 2$)$. The following data regarding medical procedures performed in the patients' home country was available: 18 cases had received a general surgical procedure, 17 cases had received orthopedic procedures, 3

Table 1. ISS Classification

\begin{tabular}{lcc}
\hline ISS & Number of Victims & Percent \\
\hline $1-8$ & 109 & 51 \\
$9-14$ & 73 & 34 \\
$16-24$ & 15 & 7 \\
$\geq 25$ & 17 & 8 \\
Total & 214 & 100 \\
\hline
\end{tabular}

cases had undergone neurosurgery, 4 cases had undergone ENT surgery, 1 case received ophthalmic surgery, and 1 case had undergone urological surgery. In Iran, 86 of these patients received orthopedic surgery (40.2\%), 25 (11.7\%) received general surgical procedures, 21 (9.8\%) underwent ENT surgical procedures, 18 cases $(8.4 \%)$ underwent plastic surgery, 15 cases $(7 \%)$ received neurosurgery, and 10 cases (4.7\%) underwent ophthalmic surgery (Figure 2).

Moreover, $25(11.7 \%)$ patients received psychiatric counseling. Only 2 cases of mortality were reported, and they occurred in emergency rooms. Only 7 cases were hospitalized in the Intensive care unit (ICU). The mean hospital stay was $13.43 \pm 19.76$ days (range $=1-230$ days). Sepsis was present in 4 cases at the time of admission. Of 185 hospitalized cases with adequate information, 37 had infected wounds. This rate was 35 out of 208 at the time of admission. Deep vein thrombosis (DVT) at the time of admission was observed in 4 cases. In 13 out of 208 examined cases, limb amputation was carried out.

\section{Discussion}

The rate of morbidity and mortality associated with explosion depends on the injured organs. ${ }^{12}$ Injury to the central nervous system is fatal. The incidence of head trauma in terrorist blast injuries ranges from $10.8 \%$ to $63 \% .{ }^{13-16}$ About $1 \%$ to $5 \%$ of civilian bombing victims die immediately after head trauma. Most patients treated in emergency departments are not badly injured, suffering only lacerations, scratches, and bruising., ${ }^{9,17}$ About $12 \%$ to $50 \%$ of victims are examined and only a small number of them (1\% to $15 \%)$ suffer abdominal or chest trauma. The high rates of hospitalization and more severe injuries are mainly observed in confined-space explosions

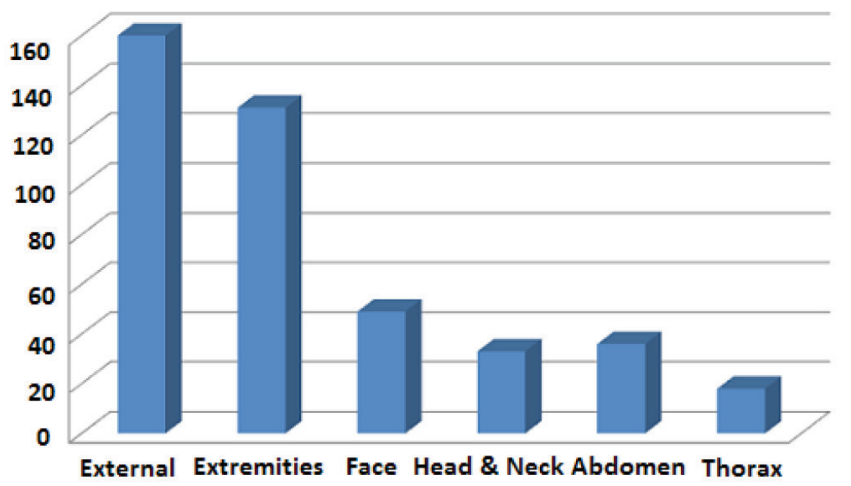

Figure 1. Top 6 Most Commonly Injured Organs (Based on ISS).

Table 2. Number of Injured Organs

\begin{tabular}{lll}
\hline Number of Injured Organs & Number of Victims & Percent \\
\hline One organ & 42 & 20 \\
Two organs & 124 & 58 \\
Three organs & 36 & 17 \\
Four organs & 12 & 5 \\
\hline Total & 214 & 100 \\
\hline
\end{tabular}




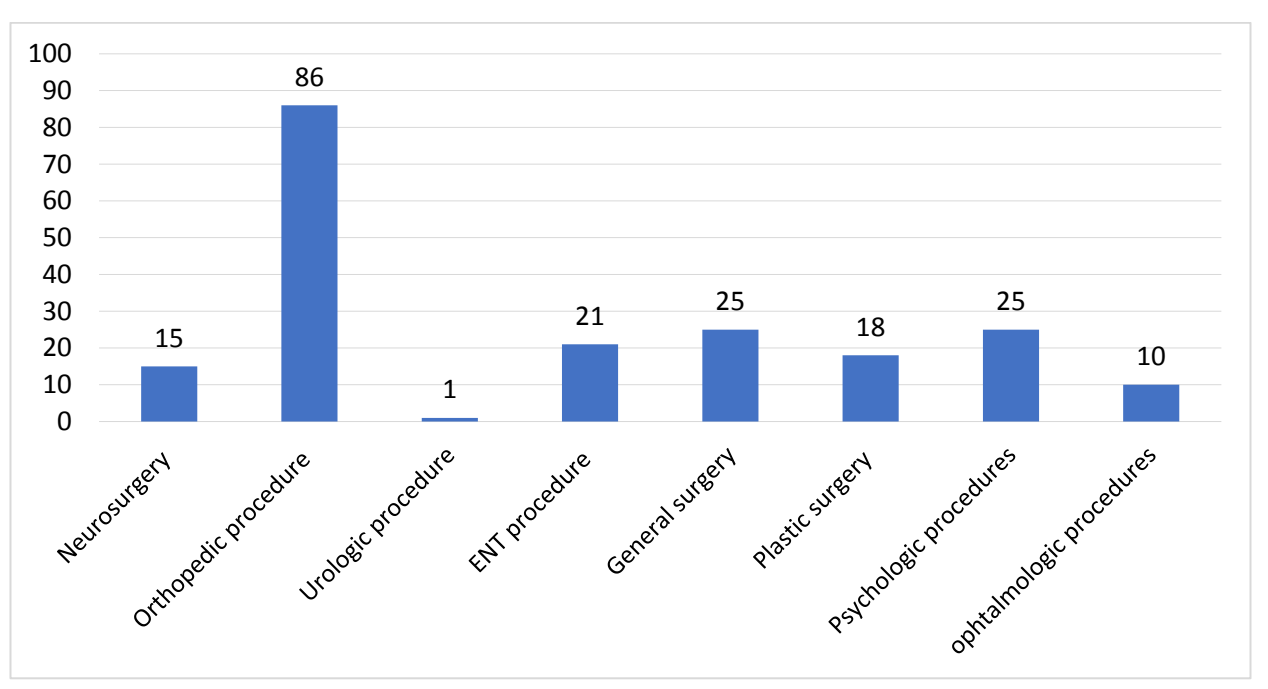

Figure 2. Number and Type of Procedures Performed for Patients.

compared to open-air blasts. ${ }^{17}$ The prevalence of chest and abdominal injuries is low (2.8\% of admitted patients), but the risk of morbidity and mortality is higher among them. Hospital morbidity and mortality in patients with blast chest trauma is $15 \%$. This rate is $19 \%$ among those with abdominal injuries. ${ }^{12}$ Victims can be classified into the following groups: those who die immediately, survivors with significant injuries (ISS >15), and overall morbidity and mortality among those who are transferred to hospitals. In this study, the in-hospital mortality rate was $2 \%$, which is an acceptable rate compared with the rates reported by other studies (7\%-8\%). ${ }^{17-19}$

The rate of casualties rises when a building collapses, trinitrotoluene (TNT) or an equivalent explosive is used, or the explosion occurs in a confined space (in cars or inside buildings). ${ }^{10,13-15}$ In a review of 29 terrorist bombings with 8346 victims and 903 immediate deaths, the casualty rate was $25 \%$ at the time of building collapse, $8 \%$ at the time of confined-space explosion without building collapse, and $4 \%$ in open-air blasts. ${ }^{17}$ Frykberg and Tepas reviewed 200 terrorist bombings with 3357 victims and found that the rate of immediate death was $13 \% .^{20}$ The mean number of victims in each bombing attack was 15 , out of which $87 \%$ immediately survived; $30 \%$ were transferred to a hospital, and $18.7 \%$ had significant injuries. The rate of mortality among immediate survivors was $2.3 \%$ and included those with severe injuries. Thus, the rate of morbidity and mortality was $12.4 \%$. Head trauma was the most common injury responsible for both early and delayed deaths (71\% and 52\%, respectively). ${ }^{20}$

Confined-space explosions and fire secondary to explosion may cause severe burns and death. Smoke inhalation injuries are not prevalent in bombings (except for confined-space bombings). ${ }^{21}$ The prevalence of burn injuries in the current study was not high either. Pulmonary blast injury (PBI) is very common in terrorist bombings, but most of these victims die at the scene due to the severity of their injuries. ${ }^{22} \mathrm{PBI}$ was observed in the lungs of only $0.6 \%$ of survivors among 2934 bombing victims. ${ }^{20}$ The autopsies of 495 victims who died in 5600 different bombing attacks in a 12-year period revealed that $66 \%$ of them suffered brain injuries, $51 \%$ had skull fractures, $47 \%$ had severe pulmonary injuries revealed by autopsy, $45 \%$ suffered tympanic membrane perforation, and $34 \%$ had liver perforation. ${ }^{23}$ Confined-space explosions cause more severe PBIs, ${ }^{17}$ and the survivors have higher ISSs and greater morbidity and mortality. ${ }^{23}$ Of 104 victims of 2 bus explosions, 7 died immediately, 51 were transferred to hospitals, 16 suffered pulmonary injuries, and 7 complained of abdominal pain (4 of these victims suffered intestinal perforations). ${ }^{12}$ Tympanic membrane perforation was observed in all those with severe injuries. At least 42 out of 80 Americans (53\%) in 1986 were injured in the LaBelle Disco bombing in Berlin, and many victims suffered tympanic membrane perforation. ${ }^{24}$ In this study, similar to other studies, explosion was the most common cause of trauma. Prevalence of gunshot injury was also high, which indicates the geographical difference of the mechanism of trauma. In the current study, the mean rate of injury was lower than the rate reported by studies evaluating terrorist attack victims at the scene. However, the number of severely injured victims was higher in this study; about $50 \%$ of victims had moderate to severe injuries, and $8 \%$ suffered extremely severe injuries. Considering the fact that $80 \%$ of patients in this study had 2 or more injured organs, it may be concluded that the usual indexes used to assess the severity of trauma are inefficient. The mean $( \pm \mathrm{SD})$ duration of hospital stay in this study was $13.43( \pm 19.76)$ days, which is a higher rate than reported in other studies ( $5 \pm 8$ days). ${ }^{25}$ This difference may be attributed to the referral of patients to the hospitals studied here or to a different pattern of trauma.

\section{Conclusion}

Patterns of attack trauma are specific and different from other trauma patterns. Blast injuries in civilians with no protective gear are more complex and severe. Clinicians and medical staff should have adequate knowledge in this respect to better manage terrorist attack victims. Special equipment and trained human resources are required for proper management. Further investigations in this respect can better elucidate this subject. 


\section{Research Highlights}

\section{What Is Already Known?}

Trauma is among the main causes of death in developing countries. Annually, about 5 million people die as the result of intentional or unintentional trauma worldwide. In recent years, due to an increase in the number of attacks, the incidence of this type of injury has risen and become a threat to global healthcare.

\section{What This Study Adds?}

Blast injuries in civilians with no protective gear are more complex and severe. Clinicians and medical staff should have adequate knowledge in this respect to better manage terrorist attack victims.

\section{Authors' Contributions}

All authors contributed equally to this research.

\section{Conflict of Interest Disclosures}

The authors declare that they have no conflicts of interest.

\section{Ethical Approval}

The protocol of the study was approved by the Medical Ethics Committee of Baqiyatallah University of Medical Sciences.

\section{Funding/Support}

None.

\section{References}

1. Jordan FB. The role of the medical examiner in mass casualty situations with special reference to the Alfred P. Murrah Building bombing. J Okla State Med Assoc. 1999;92(4):159-163. doi:10.1097/00000658-198903000-00019.

2. Rignault DP, Deligny MC. The 1986 terrorist bombing experience in Paris. Ann Surg. 1989;209(3):368-373.

3. Janak JC, Orman JA, Soderdahl DW, Hudak SJ. Epidemiology of Genitourinary Injuries among Male U.S. Service Members Deployed to Iraq and Afghanistan: Early Findings from the Trauma Outcomes and Urogenital Health (TOUGH) Project. J Urol. 2017;197(2):414-419. doi:10.1016/j.juro.2016.08.005.

4. Kluger Y. Bomb explosions in acts of terrorism--detonation, wound ballistics, triage and medical concerns. Isr Med Assoc J. 2003;5(4):235-240.

5. Kluger Y, Peleg K, Daniel-Aharonson L, Mayo A. The special injury pattern in terrorist bombings. J Am Coll Surg. 2004;199(6):875879. doi:10.1016/j.jamcollsurg.2004.09.003.

6. Arafat S, Alsabek MB, Ahmad M, Hamo I, Munder E. Penetrating abdominal injuries during the Syrian war: Patterns and factors affecting mortality rates. Injury. 2017;48(5):1054-1057. doi:10.1016/j.injury.2017.02.005.

7. Bahouth H, Ghantous Y, Rachmiel A, Amodi O, Abu-Elnaaj I. Maxillofacial Injuries Related to the Syrian War in the Civilian Population. J Oral Maxillofac Surg. 2017;75(5):995-1003. doi:10.1016/j.joms.2017.01.007.

8. Eastridge BJ, Jenkins D, Flaherty S, Schiller H, Holcomb JB.
Trauma system development in a theater of war: Experiences from Operation Iraqi Freedom and Operation Enduring Freedom. J Trauma. 2006;61(6):1366-1372. doi:10.1097/01. ta.0000245894.78941.90.

9. Hogan DE, Waeckerle JF, Dire DJ, Lillibridge SR. Emergency department impact of the Oklahoma City terrorist bombing. Ann Emerg Med. 1999;34(2):160-167. doi:10.1016/S01960644(99)70224-6.

10. Leibovici D, Gofrit ON, Stein M, et al. Blast injuries: bus versus open-air bombings--a comparative study of injuries in survivors of open-air versus confined-space explosions. J Trauma. 1996;41(6):1030-1035. doi:10.1097/00005373-19961200000015 .

11. Khoshmohabat H, Rasouli HR, Danial Z, Ghane MR. Validation of an Iranian Trauma Data Collection Form. Trauma Mon. 2016;21(5):e24686. doi:10.5812/traumamon.24686.

12. Phillips $Y$, Richmond DR. Blast injury and basic research: a brief history. In: The Textbook of Military Medicine-Conventional Warfare: Ballistic, Blast, and Burn Injuries. Washington, DC: Department of the Army, Office of the Surgeon General; 1991: $221-40$.

13. Brismar B, Bergenwald L. The terrorist bomb explosion in Bologna, Italy, 1980: an analysis of the effects and injuries sustained. J Trauma. 1982;22(3):216-220. doi:10.1097/00005373198203000-00007.

14. Caro D, Irving M. The old Bailey bomb explosion. Lancet. 1973;1(7817):1433-1435. doi:10.1016/S0140-6736(73)91753-4.

15. Mallonee S, Shariat S, Stennies G, Waxweiler R, Hogan D, Jordan F. Physical injuries and fatalities resulting from the Oklahoma City bombing. Jama. 1996;276(5):382-387. doi:10.1001/ jama.1996.03540050042021.

16. Tucker K, Lettin A. The Tower of London bomb explosion. Br Med J. 1975;3(5978):287-290. doi:10.1136/bmj.3.5978.287.

17. Arnold JL, Halpern P, Tsai MC, Smithline H. Mass casualty terrorist bombings: a comparison of outcomes by bombing type. Ann Emerg Med.2004;43(2):263-273.doi:10.1016/s0196064403007236.

18. Propper BW, Rasmussen TE, Davidson SB, et al. Surgical response to multiple casualty incidents following single explosive events. Ann Surg. 2009;250(2):311-315. doi:10.1097/ SLA.0b013e3181ae34a2.

19. Turegano-Fuentes F, Caba-Doussoux P, Jover-Navalon JM, et al. Injury patterns from major urban terrorist bombings in trains: the Madrid experience. World J Surg. 2008;32(6):1168-1175. doi:10.1007/s00268-008-9557-1.

20. Frykberg ER, Tepas JJ 3rd. Terrorist bombings. Lessons learned from Belfast to Beirut. Ann Surg. 1988;208(5):569-576. doi:10.1097/00000658-198811000-00005.

21. Quenemoen LE, Davis YM, Malilay J, Sinks T, Noji EK, Klitzman S. The World Trade Center bombing: injury prevention strategies for high-rise building fires. Disasters. 1996;20(2):125-132. doi:10.1111/j.1467-7717.1996.tb00522.x.

22. Hill JF. Blast injury with particular reference to recent terrorist bombing incidents. Ann R Coll Surg Engl. 1979;61(1):4-11.

23. Singer $P$, Cohen JD, Stein M. Conventional terrorism and critical care. Crit Care Med. 2005;33(1 Suppl):S61-65. doi:10.1097/01. CCM.0000151068.33935.3E.

24. Boehm TM, James JJ. The medical response to the LaBelle Disco bombing in Berlin, 1986. Mil Med. 1988;153(5):235-238.

25. Moini M, Rezaishiraz H, Zafarghandi MR. Characteristics and outcome of injured patients treated in urban trauma centers in Iran. J Trauma. 2000;48(3):503-507. doi:10.1097/00005373200003000-00023. 